\title{
Technique of laryngotracheal resection in subglottic stenosis
}

\author{
Erich Stoelben, Armen Aleksanyan \\ Lung Clinic, Hospital of Cologne, Chair of Thoracic Surgery, Private University of Witten/Herdecke, Köln, Germany \\ Contributions: (I) Conception and design: All authors; (II) Administrative support: E Stoelben; (III) Provision of study materials or patients: A \\ Aleksanyan; (IV) Collection and assembly of data: A Aleksanyan; (V) Data analysis and interpretation: All authors; (VI) Manuscript writing: All \\ authors; (VII) Final approval of manuscript: All authors. \\ Correspondence to: Prof. Dr. med. Erich Stoelben. Lung Clinic, Hospital of Cologne, Chair of Thoracic Surgery, Private University of Witten/ \\ Herdecke, Ostmerheimer Str. 200, 51109 Köln, Germany. Email: stoelbene@kliniken-koeln.de.
}

\begin{abstract}
Cervical stenosis of the trachea caused by tracheotomy, tumor or induced by inflammatory disease can be treated by resection and anastomosis with good early and long-term results. Involvement of the ring cartilage makes the procedure technical demanding and increases the risk of morbidity. We describe our technique of laryngotracheal resection and reconstruction and compare the perioperative results with standard trachea resection. Between January 2005 and September 2018, we performed 92 standard cervical tracheal resections and 50 laryngotracheal resection including 6 procedures with widening of the ring cartilage. The resections were realized by direct anastomosis using dorsal flaps and/or interposition of rib cartilage in the posterior part of the ring cartilage. In one case intraoperative tracheotomy and intralaryngeal stenting was used. Patient records have been analyzed for perioperative data retrospectively. The main cause for stenosis or defect of the trachea and operation is preceding tracheotomy. Idiopathic stenosis, tumors and subglottic stenosis in Wegener disease are less common. Healing of the anastomosis was not disturbed in any patient. In two patients, bronchoscopic resection of granulation tissue was necessary. Tracheotomy in the course of treatment for intralaryngeal swelling or recurrent nerve palsy was necessary in 3 patients including one intraoperative tracheotomy for glottic stenting. Postoperative tracheostomy was closed in all patients within 3 months. Pulmonary complications and persistent recurrent nerve palsy occurred in 4 and 2 of the patients, respectively. Two patients died of pulmonary complications. The laryngotracheal resection is a relevant part of cervical tracheal surgery. It can be performed without significant elevated morbidity and is able to restore lung function and quality of voice.
\end{abstract}

Keywords: Trachea; stenosis; surgery

Submitted Feb 11, 2020. Accepted for publication Mar 24, 2020.

doi: $10.21037 /$ jtd.2020.04.06

View this article at: http://dx.doi.org/10.21037/jtd.2020.04.06

\section{Introduction}

Suture of transected cervical trachea and resection with anastomosis of the trachea were published by Glück and Küster in 1881 and 1885 (1-3). At that time, the need for tracheal surgery was low and mainly due to injuries and tumors. The worldwide epidemic of poliomyelitis in the 1950 s and the increasing need of cardiac and thoracic surgery led to the introduction of intensive care and intubation with ventilation. The routine uses of ventilation by cuff armed tube and tracheostomies in the $1960 \mathrm{~s}$ produced stenosis of the trachea in an important part of this patients and necessitated investigations on the cause and prevention of this complications (4).

The dimension of this clinical challenge can by realized taking into account, that nearly 40,000 tracheotomy are performed every year in Germany (5). In about $1 \%$ to $20 \%$ of these cases narrowing and stenosis can occur (6-8). Apart from granulation tissue in the level of tracheotomy, which can easily be resected by interventional tracheoscopy, the local ablation or dilatation of benign stenosis represents rather a palliative than a long-term effective procedure (9-12). 

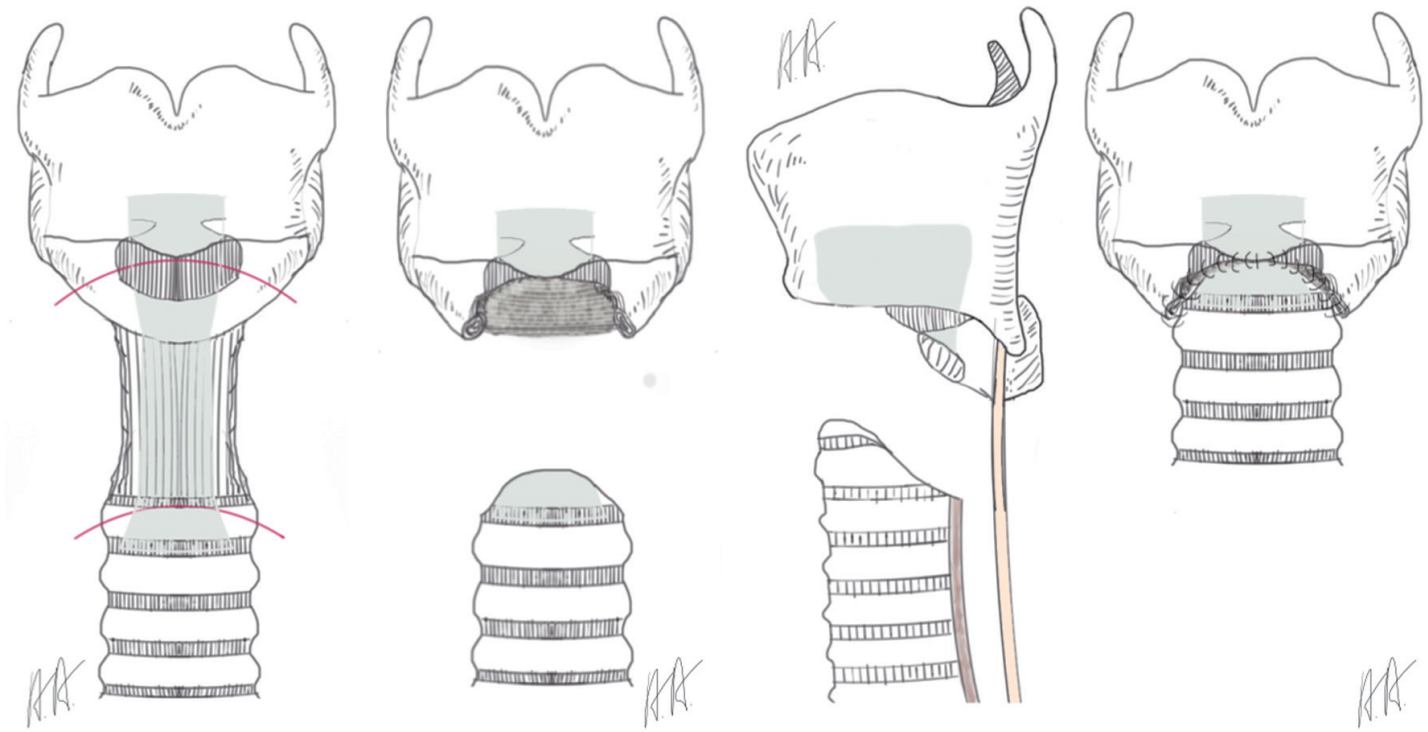

Figure 1 Laryngotracheal resection of Pearson: resection of the anterior part of the cricoid/ring cartilage.

The tracheotomy in combination with a local infection leads to a defect in the anterior wall of the trachea. During the healing process shrinkage and scarring shorten the anterior wall and produce the typical A-shape stenosis. Local dilatation or endoscopic resection may aggravate the situation. In contrast the radical resection of the stenotic segment and the anastomosis of normal trachea with healthy cartilage restore the functional anatomy of the trachea and allows a lifelong normal function (13).

The main indications for surgery of the cervical trachea are the sequelae of tracheotomy. Stenosis in the level of tracheotomy, persistent defects after decannulation and rarer cuff induced necrosis of the mucosa with subsequent stenosis has to be treated. For these patients, circular resection of the trachea and end to end anastomosis represents the standard of care with a low complication rate and good functional results (14).

The pathoanatomic situation gets more complex, if the level of tracheotomy was too high and involves the ring cartilage. Local infection and perichondritis attack the cartilage which induce edema and scarring. In this cases, surgical procedure requires the resection of the anterior part of the ring cartilage and reconstruction by the molded anterior wall of the trachea (procedure of Pearson, Figure 1) (15).

In advanced cases, the perichondritis is extended circumferentially and produce granulations tissue on the dorsal plate of the ring cartilage. The tracheoscopic view looks like a sandglass stenosis. A similar stenosis develops in patients with an idiopathic subglottic stenosis. Relapsing episodes of necrotizing mucositis and healing on the junction between trachea and ring cartilage leave a short aperture like circular stenosis. The disease is rare and middle-aged women are affected only. The necrotizing mucositis resemble the subglottic stenosis which can occur in patients with Wegener's disease (granulomatosis with polyangiitis) but in patients with idiopathic subglottic stenosis no systemic involvement or elevated autoantibodies are detectable (16).

The resection of the dorsal plate of the ring cartilage is not possible, since it carries the arytenoid cartilages and the articulation to the thyroid cartilage. Furthermore, the recurrent nerves enter the larynx in the posterior ankle between the ring and thyroid cartilage. In case of cicatrized mucosa over the posterior plate of the ring cartilage, the surgeon has to remove the pathologic tissue completely and replace it by a flap of the posterior wall of the trachea (procedure of Grillo, Figure 2) (14).

The goal of the operation is to open the subglottic space allowing respiration without a relevant resistance. In cases where the local inflammation has led to an advanced injury of the cartilage with deformation and shrinkage, the resection of the scarred mucosa may not be enough to restore the normal subglottic space. This is true also for patients, when the granulation tissue is extended upwards between the arytenoid cartilage leading to an incomplete opening of the vocal rim. The anterior split 

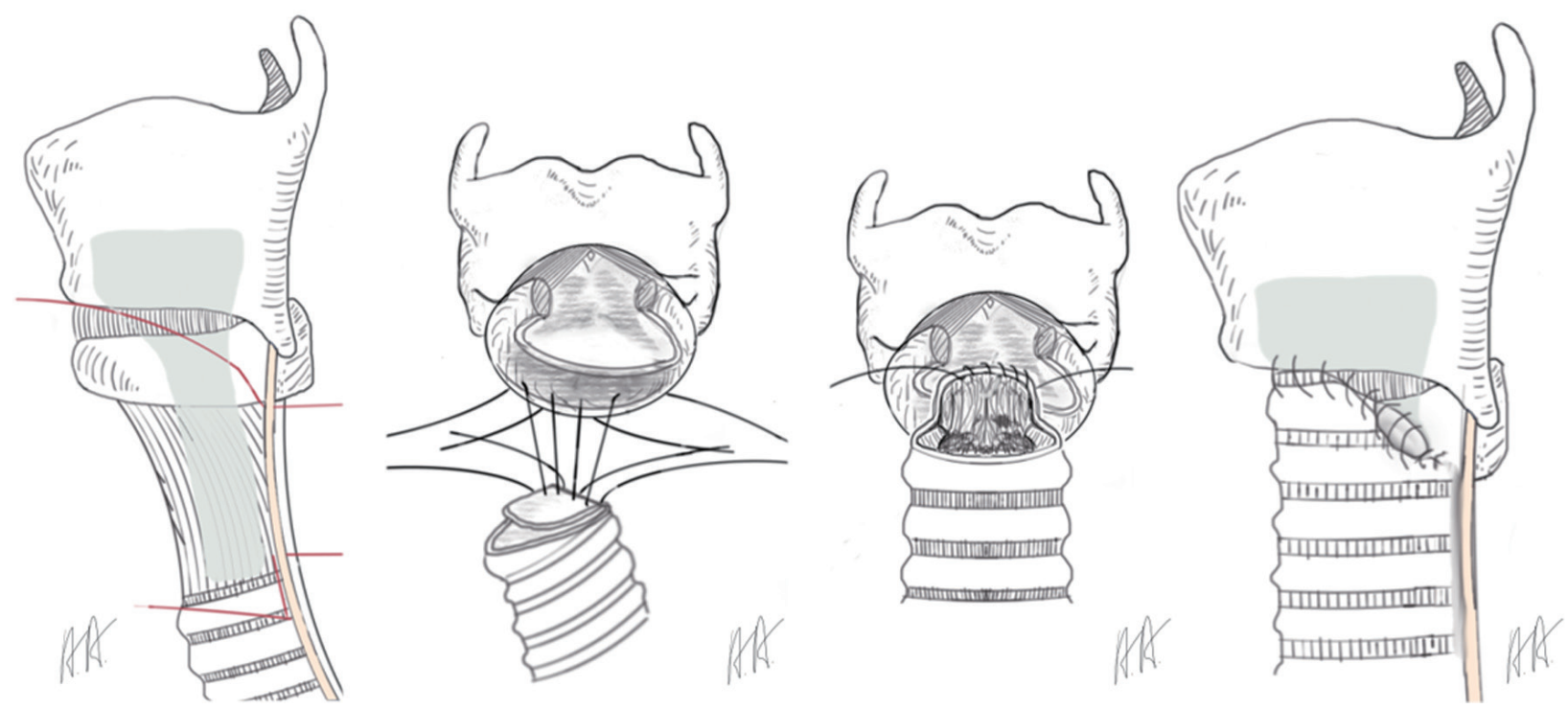

Figure 2 Laryngotracheal resection of Grillo: resection des anterior cricoid and the mucosa on the dorsal plate of the cricoid. Reconstruction with ventral tailored trachea and a dorsal flap of membranous wall.

of the vocal rim inhibits the correct closure of the vocal rim during phonation and impairs a powerful phonation permanently (17). Therefore, the division of the dorsal plate of the ring cartilage in the midline is recommended. The interposition of a $5-8 \mathrm{~mm}$ rectangular piece of cartilage allows an effective enlargement which can be compensate by the arytenoid cartilages for phonation (procedure of Couraud, Figure 3) $(18,19)$. This extended procedure of laryngotracheal resection is combined with an intralaryngeal stent in children always and in adults in most of the cases. Using intralaryngeal stents, the patient needs a tracheotomy below the tracheolaryngeal anastomosis which can entail further complications like infection, scarring and stenosis.

Essential scientific work on the pathophysiology of cuff and tracheostomy induced stenosis and the principles of treatment have been done by Hermes Grillo and Griff Pearson published in the 1960s $(20,21)$. Partial resection of the anterior part of the ring cartilage was first reported in 1964 by Ogura und Powers (22). The technical know-how for a safe laryngotracheal resection saving the recurrent nerves and the dorsal plate of the ring cartilage was developed by Gerwat und Bryce 1974 (23), by Pearson and colleagues 1975 (15) and by Grillo 1982 (14). The extension using the split of the posterior plate of the ring cartilage with interposition of a cartilage autotransplant in children was first presented by Blair Fearon und Robin Cotton (procedure of Fearon-Cotton) in the 1970s $(24,25)$ und by
Couraud in adults in the 1980s (18).

The following article should present the indication, technique and results of laryngotracheal resection. We prefer a single stage procedure without the interposition of stents or tracheotomy.

\section{Methods and patients}

This is a retrospective study on cervical tracheal surgery from 2005 to 2018 in our department (see Table 1).

The preoperative parameters are presented in Table 2.

\section{Diagnostic and therapeutic procedure}

\section{General considerations: diagnostic}

The clinical sign leading to the diagnosis is dyspnea under physical effort in combination with in- or expiratory stridor. The diagnosis is made by laryngoscopy and tracheobronchoscopy under local anesthesia and mild sedation. Avoiding general anesthesia allows the examination of the laryngeal function and the form and movement of the tracheal wall under in- and expiration. After tracheotomy and/or long prolonged hospital stay samplings for microbiological studies are recommended (26).

Lung function and radiologic investigation are used depending on the clinical picture. The indication to operate on the patient is given if the stenosis is more than $50 \%$ of 

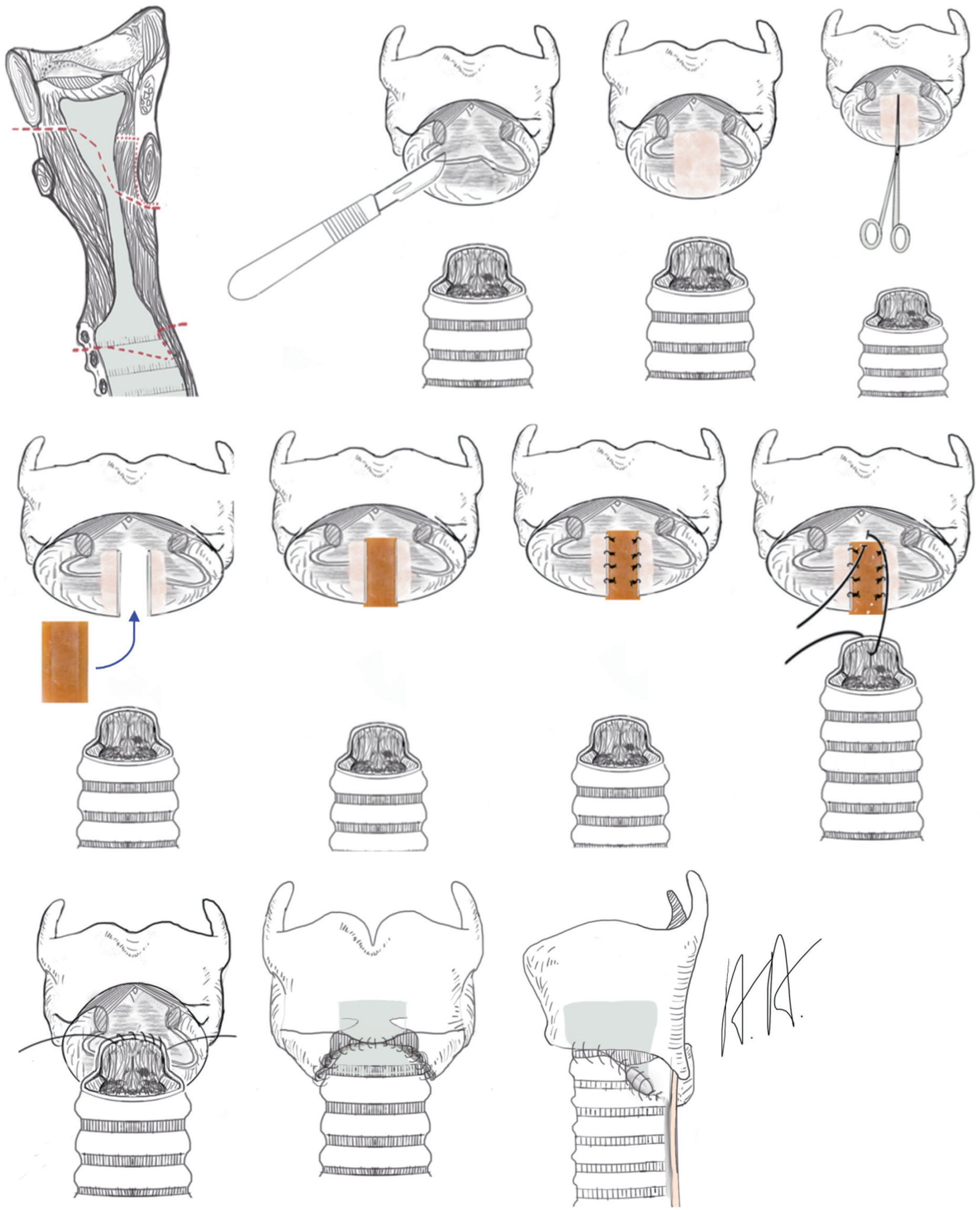

Figure 3 Laryngotracheal resection with resection of the ventral cricoid and interposition of the posterior plate of the cricoid by a cartilage transplant with two notches. 
Table 1 Experience in cervical trachea resection in our hospital 2005-2018

Resection cervical trachea $(n=142)$

Trachea resection with end-to-end anastomosis $(n=92)$

Laryngotracheal resection $(n=50)$

Procedure of Pearson $(n=37)$

Procedure of Grillo $(n=7)$

Procedure of Couraud $(n=6)$

Table 2 Preoperative data of patients with cervical trachea resection

\begin{tabular}{lc}
\hline Operation & $\begin{array}{c}\text { Laryngotracheal } \\
\text { resection }(\mathrm{n}=50)\end{array}$ \\
\hline Gender & 25 \\
Men & 25 \\
Women & 64 \\
Age (mean), years & \\
Cause of stenosis & 32 \\
Tracheotomy & 1 \\
M. Wegener & 2 \\
Malignoma & 10 \\
Idiopathic stenosis & 4 \\
Stenosis after trachea resection & 1 \\
Intralaryngeal stenosis after intubation & \\
and ventilation &
\end{tabular}

the tracheal lumen and the symptoms of dyspnea and stridor under physical stress are clinically relevant for the patients. In cases of instability of the tracheal wall it could be difficult to determine the grad of stenosis. Therefore, the functional endoscopy, lung function testing and clinical picture help to decide, if the operation can ameliorate the symptoms of the patient.

\section{General considerations: anesthesia}

Surgery starts with general anesthesia. We prefer the mechanical ventilation by laryngeal mask $(27,28)$. Patients who came on foot spontaneously breathing for surgery can be ventilated even though the trachea is extremely stenotic. Dilatation of the stenosis before tracheal intubation is not necessary and resection of the trachea is not compromised by intraluminal devices. After resection of the trachea ventilation is ensured by jet ventilation catheter passed through from the trachea to the mouth. At the end of the operation the patient respires spontaneously with the laryngeal mask in situ, which allows an endoscopic assessment of the laryngeal function and to exclude a recurrent nerve paralysis.

\section{General considerations: postoperative care}

Infection of the anastomosis can destroy the result of surgery and cab be life threatening. Therefore, we use the standardized antibiotic treatment of inhalation of tobramycin or gentamycin $80 \mathrm{mg}$ twice daily for 7 days (29). If the preoperative microbiological examinations have revealed multiresistant pathologic germs, a targeted systemic antibiotic treatment is prescribed. Endoscopic surveillance of the healing of the anastomosis and laryngeal function is performed after seen days routinely. Clinical symptoms indicating an unusual course like dyspnea, cough, stridor or secretion retention initiate a bronchoscopy promptly. Laryngeal edema may necessitate intubation and the use of low dose steroids (prednisolone $20 \mathrm{mg} / \mathrm{d}$ ) until obstruction is reduced. Tracheotomy is indicated if the treatment for swelling is not effective within seven days or in case of recurrent nerve palsy on both sides.

\section{Surgical technique: tracheal resection and end-to-end anastomosis}

The dissection of the tissue to present the trachea follows strictly the tracheal wall without preparation of the laryngeal nerves except in patients with malignant disease. The thyroid gland together with the laryngeal nerves and the inferior thyroid artery is pushed laterally. The preparation stops at the lower border of the cricoid. The cartilaginous anterior part of the trachea is mobilized downwards saving carefully the lateral segmental perfusion. After complete resection of the stenotic segment of the trachea the head of the patient is inflected, and anastomosis is carried out using monofilament resorbable suture (strength $0.15-0.25 \mathrm{~mm}$ ). We prefer a double armed thread and single running suture starting on the posterior wall and finishing in the anterior midline of the trachea. The suture line is placed in parachute technique and the thread is closed like a pulley to distribute tension along the suture line. A wound drainage is not necessary. The surrounding tissue like thyroid gland and muscles are approximated to cover the anastomosis by vital tissue. 


\section{Surgical technique: laryngotracheal resection and reconstruction}

In the extended resection group, we differentiate between three procedures although it has to be realized, that the procedures have been derived step by step from each other.

If the stenosis involves the anterior part of the cricoid, it is a typical side effect of a tracheotomy which has been created to cranial at the junction between trachea and cricoid. In these cases, we resect the anterior part of the ring cartilage saving this posterior part e.g., the dorsal plate and the recurrent nerves and perform an anastomosis between the membranous wall of the trachea and the tailored anterior wall of the trachea and the cricothyroid membrane, respectively (procedure of Pearson, Figure 1).

If the perichondritis and scarring involves the mucosa of the posterior part in the level of the cricoid with relevant thickening and obstruction, the mucosa on the dorsal plat of the ring cartilage is excised completely and the cartilage is laying open. To cover the defect of the mucosa and to avoid the scarring again, the anterior wall and the membranous wall of the trachea are customized allow a complete circular anastomosis of the mucosa (procedure of Grillo, Figure 2).

If the perichondritis has injured the cricoid completely with shrinkage and scarring, the laryngeal space can be stenotic itself. Sometimes the mucosa between the arytenoid cartilages can be involved leading to a reduced opening of the vocal cords. Therefore, resection of the mucosa has to be combined with an expansion of the larynx by splitting the posterior plate of the ring cartilage and interposition of a $5-8 \mathrm{~mm}$ measuring rectangular cartilage transplant, which is excised from the costal arch. The cartilage transplant is customized with two lateral notches which allows a stable interposition and is fixed with single stitches. The stability of the larynx relies on the stiffness of the remaining ring cartilage. For a better access to the posterior plate of the cricoid and to localize the vocals cords, it can be useful to split the thyroid cartilage in the anterior midline. At end of the procedure the thyroid cartilage is closed without an interposition. Anastomosis of the trachea to the larynx is carried out like in the procedure of Grillo. The posterior flap of the membranous part of the trachea has to be long enough to cover the defect of the mucosa sometimes up to the interarytenoid fold (procedure of Couraud, Figures 3-5).

\section{Results}

The results are presented in Table 3.

Postoperative persistent recurrent nerve palsy was documented in two cases, one after resection of a mucoepidermoid carcinoma and one after reconstruction of the larynx after complete obstruction due to perichondritis under long standing intubation and ventilation.

In seven patients laryngeal malfunction and functional stenosis due to edema and/or recurrent nerve palsy was treated by intubation and ventilation in combination with anti-inflammatory treatment for a maximum of 7 days or by intermittent tracheotomy $(\mathrm{n}=3)$. In two cases, intraoperative tracheotomy was use for complex intralaryngeal reconstruction and intraoperative silicon stenting (Figure 6). Pneumonia and respiratory insufficiency with nonintubated ventilation and intubated ventilation $(n=4)$ was the most common cause of intensive care treatment and the cause of postoperative death in two patients, one with Bechterew disease. In two cases bronchoscopy with local treatment was used to resect granulations tissue in the level of anastomosis.

\section{Discussion}

The laryngotracheal resection and reconstruction is a demanding procedure, which is indicated for patients with tracheotomy involving the ring cartilage, repeated interventions in the upper end of the trachea, idiopathic stenosis and tumors. Overall these are rare indications and need personal experience. The advantage of this operation is restoration of effective ventilation, voice and cough in one procedure. Grillo has developed the laryngotracheal resection in the $90^{\text {th }}(16)$ for the treatment of idiopathic stenosis and Couraud introduced the enlargement by splitting the anterior commissure and interposition of the posterior ring cartilage $(18,19)$. This technique was combined with an intralaryngeal silicon stent and tracheotomy. In children, this procedure is until now the standard of care, due to the smaller lumen and the higher instability of the laryngeal skeleton (30). The clinical results of this procedure are good to excellent and well documented in a number of publications (31-33).

Using the experience in surgery of the larynx in children and realizing the mechanical differences in men, the Vienna group of thoracic surgery omitted the intraoperative stenting and tracheotomy with success $(34,35)$.

The resection of the ring cartilage exposes the recurrent nerves to the risk of a mechanical injury. To avoid this complication, preparation of the trachea strongly leads along the tracheal wall. The lobes of the thyroid gland are detached from the trachea and pushed laterally together with the recurrent nerves, who crosses the branches of the 

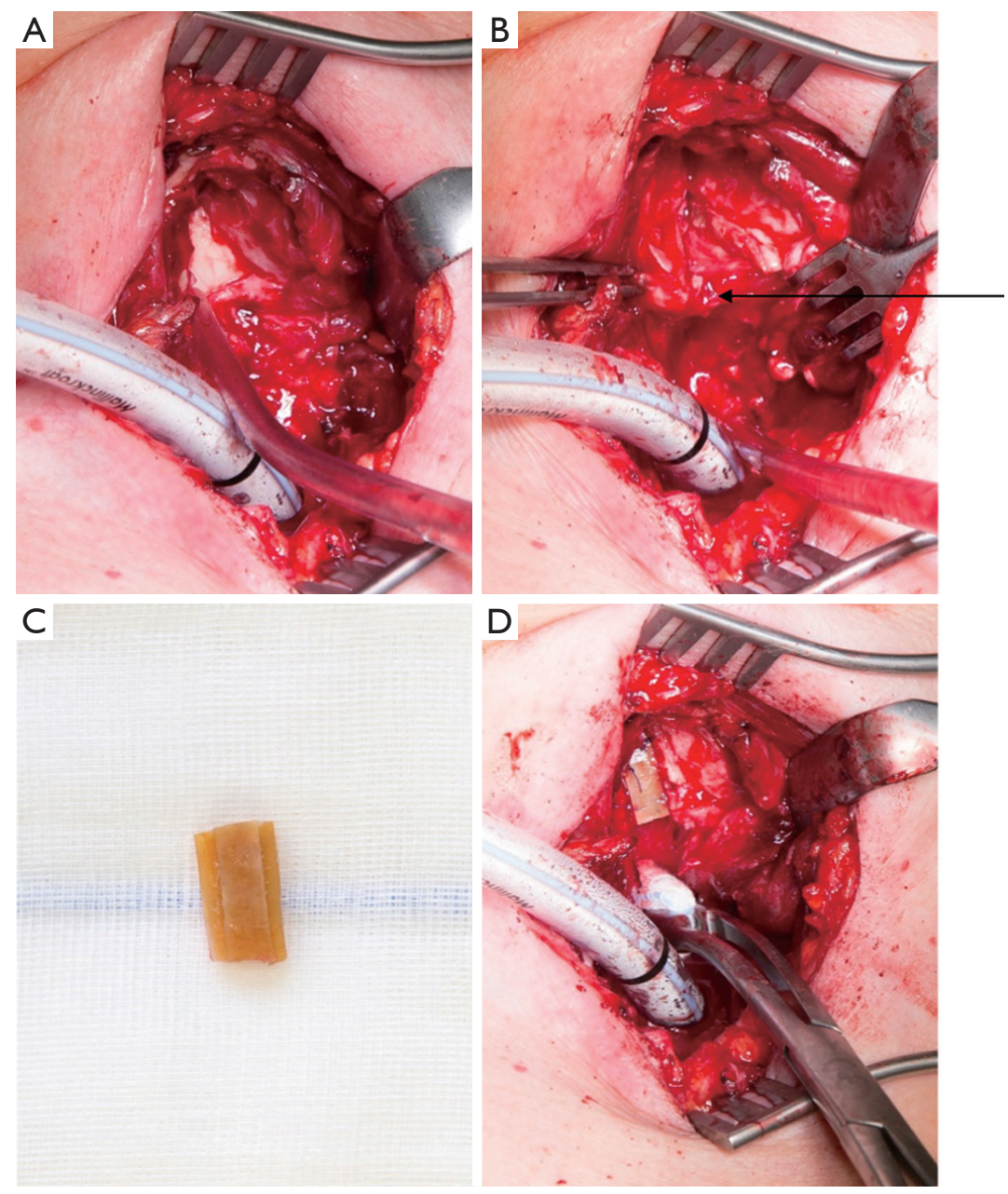

Figure 4 Intraoperative view of a laryngotracheal resection with interposition of the posterior plate of the cricoid. Intubation of the distal trachea over the operation field. (A) After resection of the anterior cricoid and the mucosa on the posterior plate exposing the cartilage. (B) After splitting the posterior plate of the cricoid. (C) Cartilage transplant from the costal arch with two lateral notches. (D) Interposition of the transplant. The black arrow indicates the dissected posterior plate of the ring cartilage.

Table 3 Postoperative results

\begin{tabular}{lc}
\hline Operation & Laryngotracheal resection $(\mathrm{n}=50)$ \\
\hline Postoperative stay $(\mathrm{d})$ & 11 \\
Complications & 0 \\
Re-trachearesection & 3 \\
Tracheotomy & 2 \\
Postoperative death & 2 \\
Revision & 4 \\
Respiratory insufficiency/pneumonia & $7 / 2$ \\
Recurrent nerve palsy intermittent/persistent & - \\
Persistent tracheotomy & - \\
\hline
\end{tabular}



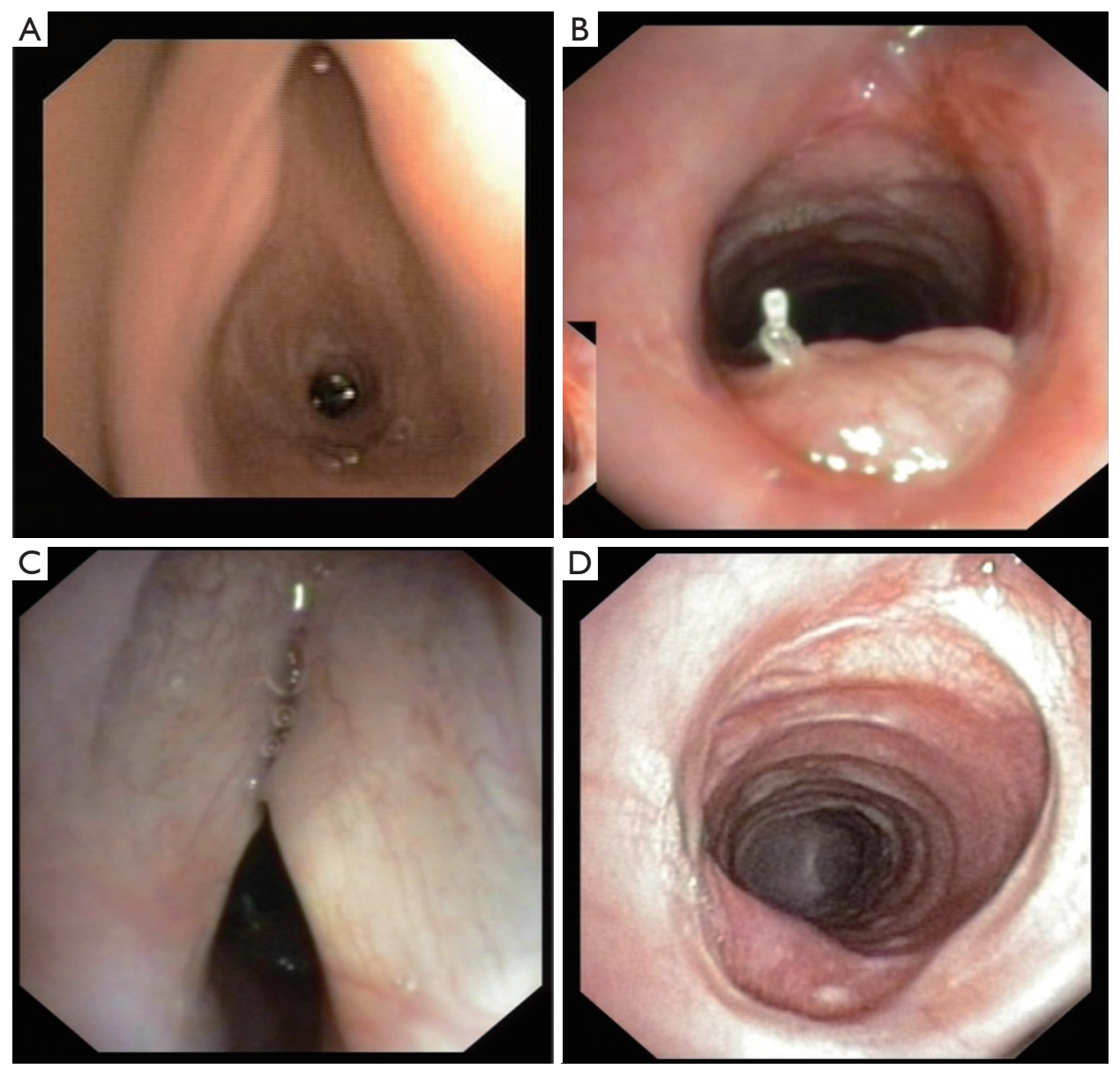

Figure 5 Female patient with granulomatous angiitis for 15 years, subglottic stenosis and repeated dilations, emergency tracheotomy for 95\% stenosis. Treatment: laryngotracheal resection with interposition of cartilage in the posterior ring cartilage (Couraud technique). (A) Preoperative laryngoscopy. (B) Postoperative tracheoscopy 4 weeks after operation showing the posterior flap of the membranous wall. (C,D) Laryngoscopy and tracheoscopy 3 months postoperatively.

inferior thyroid artery. The anterior resection of the ring cartilage must respect the dorsal plate, where the recurrent nerves enter the larynx. The median split of the dorsal plate of the ring cartilage bears no risk of nerve injury. Keeping in mind these rules, the rate of definitive recurrent nerve palsy will be low $(\mathrm{n}=2)$.

The easier technique of dissection and enlargement of the anterior commissure of the larynx without resection include the disadvantage, that the vocal folds cannot be closed anymore completely and definitely (17). Therefore, functional results are not satisfying, and this procedure is not recommended. The anterior resection of the ring cartilage together with the posterior split with cartilage interposition impairs the stability of the ring cartilage which represent the anatomical basis of the larynx. Furthermore, the cricothyroid muscles are resected who are responsible for the preload of the vocal fold. The instability of the larynx and the low preload of the vocal cords compromise the phonation indicated by a deeper voice.

A recent publication, comparing endoscopic, endoscopic in combination with local medical treatment and surgical treatment of idiopathic subglottic stenosis, confirmed the impact of surgery on vocal function. On the other hand, the respiratory function, the quality of live and risk of repeated interventions were clearly better after surgery (36).

In conclusion laryngotracheal resection delivers an effective single stage procedure for the treatment of subglottic stenosis in the main part of the patients in 

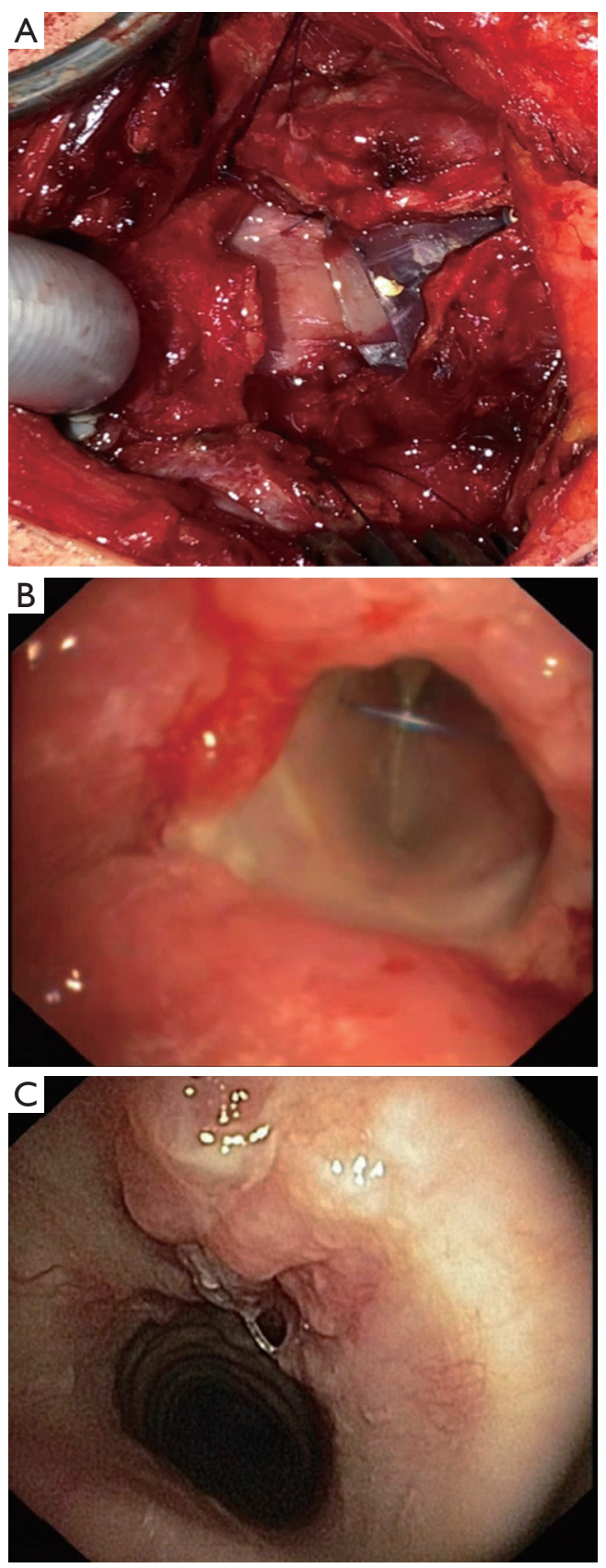

Figure 6 Female patient with perichondritis and total obstruction of the larynx after intubation and ventilation for pneumonia. Operation of Couraud with mucosectomy, interposition of the posterior ring cartilage and intraoperative silicon stenting and tracheotomy. (A) Intraoperative view after resection and silicon stenting. (B) Postoperative view from tracheotomy upwards of the silicon stent in place. (C) Postoperative tracheoscopy after removal of the stent and closure of the tracheotomy. experienced hands.

\section{Acknowledgments}

Funding: None.

\section{Footnote}

Provenance and Peer review: This article was commissioned by the Guest Editor (Servet Bölükbas) for the series "Airway Surgery", published in Fournal of Thoracic Disease. This article has undergone external peer review.

Conflicts of Interest: Both authors have completed the ICMJE uniform disclosure form (available at http://dx.doi. org/10.21037/jtd.2020.04.06). The series "Airway Surgery" was commissioned by the editorial office without any funding or sponsorship. The authors have no other conflicts of interest to declare.

Ethical Statement: The authors are accountable for all aspects of the work in ensuring that questions related to the accuracy or integrity of any part of the work are appropriately investigated and resolved.

Open Access Statement: This is an Open Access article distributed in accordance with the Creative Commons Attribution-NonCommercial-NoDerivs 4.0 International License (CC BY-NC-ND 4.0), which permits the noncommercial replication and distribution of the article with the strict proviso that no changes or edits are made and the original work is properly cited (including links to both the formal publication through the relevant DOI and the license). See: https://creativecommons.org/licenses/by-nc-nd/4.0/.

\section{References}

1. Glück T, Zeller A. Die prophylaktische Resektion der Trachea. Arch Klin Chir 1881;26:27-36.

2. Colley F. Die Resektion der Trachea. Deutsche Ztschr Chir 1885;40:150-62.

3. Küster E. Über narbige Stenose der Trachea. Zentralbl Chir 1885;13:759-60.

4. Cooper JD. Surgery of the airway: historic notes. J Thorac Dis 2016;8:S113-20.

5. Lopez-Pastorini A, Kraja O, Ludwig C, et al. [Reduction 
of Tracheotomy Associated Tracheal Stenosis by Surgical Closure of the Tracheostomy]. Pneumologie 2015;69:335-40.

6. Murphy DA, MacLean LD, Dobell AR. Tracheal stenosis as a complication of tracheostomy. Ann Thorac Surg 1966;2:44-51.

7. Stauffer JL, Olson DE, Petty TL. Complications and consequences of endotracheal intubation and tracheotomy. A prospective study of 150 critically ill adult patients. Am J Med 1981;70:65-76.

8. Ludwig C, Stoelben E. A new classification of bronchial anastomosis after sleeve lobectomy. J Thorac Cardiovasc Surg 2012;144:808-12.

9. Paris F, Borro JM, Tarrazona V, et al. Management of non-tumoral tracheal stenosis in 112 patients. Eur J Cardiothorac Surg 1990;4:265-8; discussion 268-9.

10. Macchiarini P, Chapelier A, Lenot B, et al. Laryngotracheal resection and reconstruction for postintubation subglottic stenosis. Lessons learned. Eur J Cardiothorac Surg 1993;7:300-5.

11. Grillo HC, Donahue DM, Mathisen DJ, et al. Postintubation tracheal stenosis. Treatment and results. J Thorac Cardiovasc Surg 1995;109:486-92; discussion 492-3.

12. Ernst A, Feller-Kopman D, Becker HD, et al. Central airway obstruction. Am J Respir Crit Care Med 2004;169:1278-97.

13. Friedberg SA, Griffith TE, Hass GM. Histologic changes in the trachea following tracheostomy. Trans Am Laryngol Assoc 1965;86:53-68.

14. Grillo HC. Primary reconstruction of airway after resection of subglottic laryngeal and upper tracheal stenosis. Ann Thorac Surg 1982;33:3-18.

15. Pearson FG, Cooper JD, Nelems JM, et al. Primary tracheal anastomosis after resection of the cricoid cartilage with preservation of recurrent laryngeal nerves. J Thorac Cardiovasc Surg 1975;70:806-16.

16. Grillo HC, Mark EJ, Mathisen DJ, et al. Idiopathic laryngotracheal stenosis and its management. Ann Thorac Surg 1993;56:80-7.

17. Terra RM, Minamoto H, Carneiro F, et al. Laryngeal split and rib cartilage interpositional grafting: treatment option for glottic/subglottic stenosis in adults. J Thorac Cardiovasc Surg 2009;137:818-23.

18. Couraud L, Hafez A, Velly JF, et al. Current reconstructive management of subglottic stenosis of the larynx with reference to sixty consecutively treated cases. Thorac Cardiovasc Surg 1985;33:263-7.
19. Couraud L, Jougon JB, Velly JF. Surgical treatment of nontumoral stenoses of the upper airway. Ann Thorac Surg 1995;60:250-9; discussion 259-60.

20. Pearson FG, Goldberg M, da Silva AJ. Tracheal stenosis complicating tracheostomy with cuffed tubes. Clinical experience and observations from a prospective study. Arch Surg 1968;97:380-94.

21. Cooper JD, Grillo HC. The evolution of tracheal injury due to ventilatory assistance through cuffed tubes: a pathologic study. Ann Surg 1969;169:334-48.

22. Ogura JH, Powers WE. Functional Restitution of Traumatic Stenosis of the Larynx and Pharynx. Laryngoscope 1964;74:1081-110.

23. Gerwat J, Bryce DP. The management of subglottic laryngeal stenosis by resection and direct anastomosis. Laryngoscope 1974;84:940-57.

24. Fearon B, Cotton R. Surgical correction of subglottic stenosis of the larynx in infants and children. Progress report. Ann Otol Rhinol Laryngol 1974;83:428-31.

25. Cotton R. Management of subglottic stenosis in infancy and childhood. Review of a consecutive series of cases managed by surgical reconstruction. Ann Otol Rhinol Laryngol 1978;87:649-57.

26. Wolter A, Ludwig C, Beckers F, et al. Influence of nosocomial infections on resection of tracheal stenosis after tracheotomy. Pneumologie 2012;66:7-11.

27. Krecmerova M, Schutzner J, Michalek P, et al. Laryngeal mask for airway management in open tracheal surgery-a retrospective analysis of 54 cases. J Thorac Dis 2018;10:2567-72.

28. Schieren M, Egyed E, Hartmann B, et al. Airway Management by Laryngeal Mask Airways for Cervical Tracheal Resection and Reconstruction: A Single-Center Retrospective Analysis. Anesth Analg 2018;126:1257-61.

29. Ludwig C, Riedel R, Schnell J, et al. Inhalation with Tobramycin to improve healing of tracheobronchial reconstruction. Eur J Cardiothorac Surg 2009;35:797-800; discussion 800.

30. Alshammari J, Monnier P. Airway stenting with the LT-Mold for severe glotto-subglottic stenosis or intractable aspiration: experience in 65 cases. Eur Arch Otorhinolaryngol 2012;269:2531-8.

31. Ashiku SK, Kuzucu A, Grillo HC, et al. Idiopathic laryngotracheal stenosis: effective definitive treatment with laryngotracheal resection. J Thorac Cardiovasc Surg 2004;127:99-107.

32. Morcillo A, Wins R, Gomez-Caro A, et al. Single-staged laryngotracheal reconstruction for idiopathic tracheal 
stenosis. Ann Thorac Surg 2013;95:433-9; discussion 439.

33. Gnagi SH, Howard BE, Anderson C, et al. Idiopathic Subglottic and Tracheal Stenosis: A Survey of the Patient Experience. Ann Otol Rhinol Laryngol 2015;124:734-9.

34. Hoetzenecker K, Schweiger T, Roesner I, et al. A modified technique of laryngotracheal reconstruction without the need for prolonged postoperative stenting. J Thorac
Cardiovasc Surg 2016;152:1008-17.

35. Hoetzenecker K, Klepetko W. Subglottic Resections: How I Teach It. Ann Thorac Surg 2018;106:1-7.

36. Gelbard A, Anderson C, Berry LD, et al. Comparative Treatment Outcomes for Patients With Idiopathic Subglottic Stenosis. JAMA Otolaryngol Head Neck Surg 2020;146:20-9.

Cite this article as: Stoelben E, Aleksanyan A. Technique of laryngotracheal resection in subglottic stenosis. J Thorac Dis 2020;12(10):6152-6162. doi: 10.21037/jtd.2020.04.06 